\title{
A CONSTITUIÇÃO DE UM SUBCAMPO ESPORTIVO: O CASO DA GINÁSTICA RÍTMICA
}

\author{
THE CONSTITUTION OF A SPORTS SUBFIELD: THE CASE OF RHYTHMIC \\ GYMNASTICS
}
EL ESTABLECIMIENTO DE UN SUBCAMPO DE LOS DEPORTES: EL CASO DE LA GIMNASIA RÍTMICA

Bruna Paz*, Juliano de Souza*, leda Parra Barbosa-Rinaldi*

Palavras chave:

Ginástica.

Sociologia.

Pierre Bourdieu.

Keywords:

Gymnastics.

Sociology.

Pierre Bourdieu.

Palabras clave: Gimnasia.

Sociología.

Pierre Bourdieu.

\begin{abstract}
Resumo: O objetivo deste artigo é apresentar a trajetória da ginástica rítmica (GR) como um subcampo do campo esportivo. Para o desenvolvimento do texto, mobilizamos uma série de textos, livros e artigos sobre a GR, materiais estes que, posteriormente, foram articulados a partir do referencial teórico de Pierre Bourdieu. 0 texto está dividido em três seções. Na primeira delas, apresentamos a GR como um subcampo esportivo, expondo suas características e trajetória esportiva. Já na segunda parte, são problematizados aspectos relativos ao habitus que circunda a modalidade. Por fim, descrevemos a relação entre os agentes dominados e dominantes na modalidade, sob a perspectiva dos países e equipes que estruturam as dinâmicas e lutas no interior desse subcampo.
\end{abstract}

Abstract: This article presents the trajectory of $R G$ as a subfield of the sports field. We used a number of texts, books and articles on RG, which were interconnected around the theoretical reference of Pierre Bourdieu. The text is divided into three sessions. The first session presents RG as a sports subfield, describing its characteristics and its history as a sport. The second part discusses aspects related to the habitus surrounding that sport. Finally, we describe the relationship between dominated and dominant agents in the modality from the perspective of the countries and teams that structure the dynamics and struggles within that subfield.

Resumen: El objetivo de este artículo es presentar la trayectoria de la Gimnasia Rítmica (GR) como un subcampo del campo deportivo. Para desarrollarlo, hemos movilizado una serie de textos, libros y artículos sobre GR, materiales que, posteriormente, fueron articulados a partir del marco teórico de Pierre Bourdieu. El texto se divide en tres secciones. En la primera, se presenta a la GR como un subcampo deportivo, exponiendo sus características y su trayectoria deportiva. En la segunda parte, se problematizan aspectos relativos al habitus que rodea a la modalidad. Por último, se describe la relación entre los agentes dominados y dominantes en esta modalidad, desde la perspectiva de los países y los equipos que estructuran las dinámicas y luchas dentro de ese subcampo.
*Universidade Estadual de Maringá. Maringá, PR, Brasil. E-mail: paz.bruna77@gmail.com; julianoedf@yahoo.com.br; parrarinaldi@ hotmail.com.

Recebido em: 24-05-2017 Aprovado em: 13-04-2018

DOI: http://dx.doi.org/10.22456/1982-8918.73658 (c) (1) (8) Licence 


\section{INTRODUÇÃO}

A ginástica rítmica (GR) como prática social organizada possui elementos estruturais que a tornam parte de um universo esportivo mais amplo, o que não significa negar suas especificidades que lhe garantem singularidade como objeto de estudo da área da Educação Física. Nessa dialética entre o geral e o específico, aponta-se sua relação com o treinamento de alta performance, com os processos pedagógicos, com a formação profissional, com a cultura esportiva global, entre outras temáticas adjacentes que estimulam novas análises e interpretações sobre a modalidade.

O presente texto se circunscreve ao âmbito dessas possibilidades analíticas abertas e visa a uma apreensão da história da GR à luz da Teoria dos Campos de Bourdieu, aqui entendida como uma abordagem que tem "[...] como ponto central a relação, de mão dupla, entre as estruturas objetivas (dos campos sociais) e as estruturas incorporadas (do habitus)" (BOURDIEU, 1996, p.10). Conforme apontam Souza e Marchi Júnior (2010), essa teoria contribuiu para o desenvolvimento do campo científico da Sociologia do Esporte, uma vez que Bourdieu escreveu textos sobre o assunto e dedicou alguns números da revista Actes de La Recherche em Sciences Sociales para discussão das práticas e consumos esportivos.

$\mathrm{Na}$ esteira das potencialidades teórico-metodológicas abertas por esse referencial na área de Educação Física é que assumimos como objetivo neste artigo apresentar a trajetória da GR como um subcampo do campo esportivo, num diálogo com o programa bourdieusiano para Sociologia do Esporte (BOURDIEU, 1983a) e com pesquisas já desenvolvidas a partir desse quadro teórico (SOUZA; MARCHI JÚNIOR, 2010).

Para o desenvolvimento do artigo, mobilizamos uma série de textos, livros e artigos sobre a GR, que, posteriormente, foram articulados a partir do referencial teórico supracitado. O texto está dividido em três seções. Na primeira, apresentamos a GR como um subcampo esportivo, expondo suas características, o desenvolvimento da modalidade e sua trajetória esportiva. Já na segunda parte, são problematizados aspectos relativos ao habitus que circunda a modalidade. Por fim, descrevemos a relação entre os agentes dominados e dominantes na modalidade, sob a perspectiva dos países e equipes que estruturam as dinâmicas e lutas no interior desse subcampo.

\section{A GR COMO UM SUBCAMPO ESPORTIVO}

A GR é um desporto que se destaca por permitir ao corpo o uso da arte, da criatividade e de capacidades físicas a partir de sua estrutura trifásica, envolvendo acompanhamento musical, manejo de aparelho e elementos corporais (PIRES, 2003), em uma dinâmica que foi constituindo-se ao largo da história em correspondência estreita com uma série de mudanças estruturais e sociais levadas a cabo no campo esportivo no último século.

Tem-se então, nesse sentido, que o entendimento do processo histórico da modalidade permite compreendê-la com maior propriedade, sendo uma das primeiras condições desse tipo de abordagem o esforço de (re)conhecer, dos diferentes ângulos possíveis, os problemas que são apresentados sobre este espaço social que é o campo esportivo e no qual a GR se encontra circunscrita. Paralelamente a essa investida, há a necessidade também de considerar, mesmo que em linhas bastante gerais, as produções sociológicas e epistemológicas reservadas ao campo que está se investigando (BOURDIEU, 2000; SOUZA; MARCHI JÚNIOR, 2017). 
Segundo Lourenço (2003, p. 16), a modalidade de GR começou a conquistar espaço internacional a partir do século XX, visando "[...] a busca da melhor forma de executar seus movimentos precisos e de como avaliar esses movimentos como a preocupação constante entre estudiosos e apaixonados por este esporte". A autora acrescenta que a fluência e dinâmica dos movimentos rítmicos, contrários aos movimentos masculinos nos quais a força predominava, marcaram o surgimento dessa modalidade.

Depreende-se disso que a prática exclusivamente feminina em competições oficiais desse esporte marca uma potencial necessidade de garantir princípios de feminilidade aos movimentos, preservando, de certa forma, o espaço conquistado pela mulher no universo gímnico competitivo. Contudo, para além da proteção desse espaço, é refletido nessa prática o habitus materializado nos movimentos corporais, assegurando a ritmicidade, a harmonia entre música e movimento, a leveza e fluência dos movimentos e a flexibilidade, características associadas socialmente à cultura corporal feminina e que são manifestas nas coreografias da GR. Para além então dos interesses adjacentes a essa lógica, que se contrapõem a um quadro mais amplo de mudanças nesse esporte, o que está em jogo é a preservação da história do subcampo da GR e de seus agentes dominantes e dominados no sentido de fazer valer as conquistas, crenças e particularidades construídas nesse percurso histórico.

Agregando mais elementos analíticos ao cenário, é importante destacar que, em sua história, a GR foi influenciada por quatro correntes do pensamento (Dança, Artes Cênicas, Música e Pedagogia), evidenciando a existência de um sistema de tensões e discursos, refletidos nas tomadas de posição dos inúmeros mestres que contribuíram para criação e desenvolvimento da modalidade (BARBOSA-RINALDI; MARTINELLI; TEIXEIRA, 2009).

Nesse percurso, Jean-Georges Noverre (1727-1810), francês, dançarino e amante do ballet clássico, desenvolveu o conceito do corpo como uma forma de expressão, e François Delsarte (1811-1871), também francês, lançou a ideia da expressão dos sentimentos por meio dos movimentos corporais (LOURENÇO, 2003).

De acordo com Hernández e Bouza (1982), a bailarina Isadora Duncan (1877-1927) criou a dança moderna, além de quebrar tabus e dar a devida importância ao movimento natural e à liberdade de expressão, ao passo que Emile-Jacques Dalcroze (1865-1950), músico e professor, concebeu a prática a partir de uma combinação entre música e dança. Ambos contribuíram decisivamente para o surgimento da modalidade.

Nesse cenário, tais correntes, determinantes para o desenvolvimento desse esporte, impulsionaram países da Europa como dominantes na modalidade até a década de 1980, especialmente Bulgária e União Soviética. Porém, após a dissolução da União Soviética 0 predomínio foi dividido com outros países que passaram a assumir a GR como esporte de alcance massivo, a exemplo de Rússia, Bielorrússia, Azerbaijão, Ucrânia e Bulgária, que desde então monopolizam os pódios e medalhas nas competições internacionais (FEDERAÇÃO INTERNACIONAL DE GINÁSTICA, 2016).

Surgida na Europa no século XIX, em meados dos anos 1940, a GR torna-se um desporto competitivo com o primeiro campeonato nacional em 1942 na URSS (FEDERAÇÃO INTERNACIONAL DE GINÁSTICA, 2016). Em 1952, foi criada a Liga Internacional de Ginástica Moderna (LIGIM), reconhecida pela FIG, com o intuito de divulgar internacionalmente a modalidade, e uma década depois foi realizado o primeiro campeonato mundial de GR, em 
Budapeste, na Hungria, no ano de 1963 (BARBOSA-RINALDI; MARTINELLI; TEIXEIRA, 2009). Já no certame olímpico, a modalidade foi inserida em 1984 nos Jogos de Los Angeles com provas individuais e em 1996 nos Jogos de Atlanta com provas de conjunto (LAFFRANCHI, 2001; LOURENÇO, 2010). De certo modo, esse processo associa-se ao movimento vivido pelo jogo/esporte no sentido de transição de uma prática corporal hedonista para uma prática corporal mais ascética (BOURDIEU, 1983b), de uma prática com fins mais amadores para uma prática profissional (MARCHI JÚNIOR, 2001; SOUZA; MARCHI JÚNIOR, 2017).

Esse conjunto de ações, por conseguinte, remete a um espaço simbólico de práticas sociais, composto por estruturas e agentes sociais interligados. Trata-se de um locus no qual interesses estão investidos na figura de instituições que se movimentam segundo leis próprias desse universo. Em outras palavras, a estrutura da GR remete a um subcampo que tem suas regras, princípios e hierarquias definidos a partir de confrontos e tensões construídos pelas relações de seus próprios atores sociais, a propósito dos demais campos sociais que se constituem como espaços de lutas, de interesses e de necessidades estabelecidas de acordo com os seus membros (BOURDIEU, 2004).

De modo geral, é possível afirmar que a GR apresenta características estruturais e de regulamentação comuns às demais modalidades esportivas, pois é regulamentada por uma entidade internacional, apresenta um calendário de competições, bem como regras específicas. Ao tratar da GR como um subcampo esportivo, nota-se que suas regras Ihe garantem relativa autonomia para organizar suas dinâmicas, de modo a garantir ações e estilizações que lhe são específicas. Como exemplo, destacamos o uso de collants que combinam com uma história a ser contada por música e movimentos, ou o uso extremo da flexibilidade.

Essa regulamentação prevê ainda uma lógica dos usos corporais nos treinamentos e competições por aparelhos específicos na GR. Isto é, a cada ciclo olímpico, juntamente com as alterações nos aspectos técnicos da modalidade, é reorganizada a distribuição dos aparelhos que deverão ser utilizados nos próximos quatro anos, para as coreografias individuais e de conjuntos. Segundo Pereira (2013), tais regras influenciam as práticas corporais que atletas e treinadoras definem em suas rotinas diárias. Nesse cumprimento rígido também se encontram as exclusões naturais da modalidade, já que aquelas que não atendem a técnica específica, 0 biotipo ou, até mesmo, a dominância da lateralidade, representam a parcela de ginastas não aptas a competir, caracterizando um processo excludente.

Toledo e Antualpa (2016) revelam que os quatro anos dos ciclos são insuficientes para a modalidade, já que a evolução dos elementos é constante e os ajustes da regulamentação são feitos por cartas (não totalmente difundidas e socializadas) que redefinem o código de pontuação. Assim, aqueles países que estão mais próximos da organização geral do esporte passam a ser privilegiados, pois para eles as informações chegam mais rapidamente. Segundo Bourdieu (2000), as disputas internas no campo reproduzem os combates entre classes dominantes e dominadas:

A cultura dominante contribui para a integração real da classe dominante (assegurando uma comunicação imediata entre todos os seus membros e distinguindo-os das outras classes); para a integração fictícia da sociedade no seu conjunto, portanto, à desmobilização (falsa consciência) das classes dominadas; para a legitimação da ordem estabelecida por meio do estabelecimento das distinções (hierarquias) e para a legitimação dessas distinções (BOURDIEU, 2000, p. 10). 
Esse princípio se aplica bem ao entendimento da GR, pois nesta lógica, para representar cada país nas competições organizadas pela FIG, os países com representatividade na modalidade constituem confederações que regem e organizam suas atividades, no caso do Brasil, a Confederação Brasileira de Ginástica (CBG). Todas as confederações têm suas federações que configuram certo organograma, porém, cada uma delas busca desenvolver a estratégia de difusão legítima do esporte, bem como permitir um ciclo eficiente de renovação de atletas de alto nível. Essa forma de organização, por sua vez, preserva a relativa autonomia do campo esportivo, constituído por entidades autoadministrativas e reguladoras desse espaço, entidades essas subordinadas a intenções próprias (BOURDIEU, 1983b).

É nesse sentido de autonomia que uma das possibilidades para manter a prática esportiva da GR tem se concretizado a partir da realização de eventos oficiais com caráter de apresentação e/ou competição com regulamentos adaptados facilitando maior envolvimento de diferentes ginastas (PATRÍCIO; BORTOLETO; CARBINATTO, 2016). No contexto nacional tais ações têm como base a ideia do que já é realizado pela FIG, buscando respeitar as especificidades do país.

Um dos desdobramentos desses eventos seria uma maior divulgação da GR para além dos círculos restritos, muito embora não venham recebendo devida atenção por parte da CBG e das próprias federações, diferentemente do que é registrado em países que assumem a ginástica como esporte nacional (PATRÍCIO; BORTOLETO; CARBINATTO, 2016). Nesses países, tanto a massificação quanto a formação de jovens talentos são articulados a um processo de aprendizagem esportiva mais amplo na modalidade, o que, por conseguinte, não implica considerar que o segundo processo seja resultado do primeiro.

Diante do exposto, temos então que diferentes perspectivas regulamentam o processo de aprendizagem da modalidade, estimulando o surgimento de culturas próprias e específicas à GR. Esses comportamentos distintos, por sua vez, estão associados a interesses e a uma identidade própria à modalidade, carecendo de uma problematização mais refinada e a ser constituída em termos de habitus. É a essa análise que nos voltamos a partir de agora.

\section{HABITUS CIRCUNDANTE DA GR}

De acordo com Bourdieu (1996, p. 22), habitus podem ser definidos mais precisamente como "[...] princípios geradores de práticas distintas e distintivas - o que o operário come, e, sobretudo sua maneira de comer, o esporte que pratica e sua maneira de praticá-lo, suas opiniões políticas e sua maneira de expressá-las [...]".

Nessa esteira, Souza e Marchi Júnior (2010, p. 301) sugerem que o habitus se faz presente em um campo estruturado, se tratando "[...] de um corpo socializado, um corpo estruturado, um corpo que incorporou [...]" dada realidade. Funciona como "[...] um programa de percepção, classificação e organização da ação; uma espécie de força que mantém e sustenta determinada ordem social". Neste sentido, é possível identificar na estrutura da GR elementos estruturantes do habitus das atletas. Tal análise, por sua vez, não só pode como deve levar em conta os treinamentos, as características e comportamentos das ginastas.

Sobre o treinamento, Laffranchi (2001) descreve que na GR há uma subdivisão de tarefas e, por isso, os treinos estão organizados em técnicos com montagem de coreografias 
e execução de elementos específicos; preparação física que se preocupa com as capacidades físicas, principalmente da flexibilidade; e sessões de ballet e/ou expressão corporal para atender as necessidades artísticas das séries.

Entretanto, há horários específicos e distribuídos conforme as características de cada escola, da filosofia e perfil de trabalho de cada país. Segundo Pereira (2013), é possível perceber as preocupações de cada escola de ginástica quando as equipes búlgaras, russas e espanholas são comparadas. A autora declara a Bulgária com coreografias que privilegiam a arte, a Rússia com séries muito técnicas e a Espanha com estímulo à cultura em suas equipes.

Esse fato pode definir habitus diferenciados em um mesmo subcampo do esporte. O entendimento consiste em estabelecer ações que são prioritárias, como os aspectos dos treinamentos, mas que respeitam a história e a filosofia de trabalho de cada país. Cavalcanti (2008) revela que, muitas vezes, mesmo sendo muito importante a parte artística da GR, o corpo e a criatividade são aprisionados por regras e obrigações. Contudo, a essência dos países citados busca quebrar com essa rigidez a partir de um olhar para além da técnica dos elementos corporais e manejos de aparelhos.

Sobre as características das ginastas, identifica-se um biotipo magro de pernas alongadas associado à necessidade de ser flexível (RÓBEVA; RANKÉLOVA, 1991), garantindo uma melhor visualização na quadra e, consequentemente, uma maior valorização dos movimentos. $O$ corpo é tratado como um elemento fundamental, muitas vezes, com demandas excessivas de cuidado desde idades mais novas (LAFFRANCHI, 2001).

A estrutura da GR (elementos corporais, aparelhos e música) é estabelecida como característica própria da modalidade, mas estruturada com o pano de fundo de uma perspectiva estética do esporte. Ao citar os aparelhos oficiais, Paoliello e Toledo (2010) afirmam que a relação corpo e aparelho se dará mediante as características de cada ginasta. Em algumas coreografias, a ginasta esconde suas limitações corporais com uma exagerada utilização de manejos, enquanto outras utilizam movimentos corporais como um escudo para as limitações no manejo de aparelhos.

Assim, determinados comportamentos são percebidos entre os grupos de ginastas, tais como a preocupação com um corpo magro, o uso de aparelhos que "combinem" com collants e músicas, e ainda as preocupações estéticas. Para além dos cuidados técnicos, a GR é uma modalidade esportiva que está vinculada a um habitus fortemente estético, pautado na definição do corpo magro com pernas alongadas, ou até mesmo no uso de collants suntuosos que, muito embora não sejam exigidos pelo código de pontuação, configuram uma cobrança subjetiva da modalidade. Não por acaso o próprio código de pontuação faz tentativas de objetivar os princípios estéticos, quando sintetiza e conceitua harmonia entre música e movimento, ou faz referência a critérios para o valor artístico.

Segundo Porpino (2004), a GR estabelece uma vivência estética quando busca garantir exuberância em suas coreografias pensadas por treinadoras e ginastas, mas avaliadas por outros olhares. Assim, o que pode ser belo e exuberante para uns pode ter outra análise quando percebido por outros atores.

Sobre a inquietação do corpo magro, a imagem corporal passa a ser um tema refletido constantemente entre grupos de ginastas, com a preocupação com o não engordar e do que é 
autorizado a comer. Assim, por mais que haja um acompanhamento nutricional dessas atletas, elas ainda acreditam que têm a necessidade de emagrecer (LAFFRANCHI, 2001). O corpo idealizado ou desejado incorpora contornos e medidas impostos pelos critérios de pontuação (ROMA, 2003), somados à imagem corporal de um corpo de uma campeã.

Ao detalhar um atributo alheio às regras do código de pontuação, mas fundamental para a avaliação da GR, vem à tona a mudança dos collants. Segundo Lourenço (2010), inicialmente, não eram permitidos brilhos e/ou transparências, posteriormente, foram liberados macacões até o tornozelo e, atualmente, os brilhos e rendas fazem dos collants vestimentas que chamam a atenção do público em geral. Isto é, esses apetrechos não somam oficialmente na pontuação, mas identificam ginastas que podem se destacar em suas composições. Além disso, esses utensílios também somam um traço importante para a GR, que é o "distintivo de feminilidade", pois, mesmo com todas as exigências corporais, a graça e a beleza na execução devem prevalecer (BOAVENTURA, 2011).

Este "distintivo de feminilidade" está baseado nas proposições que fundamentaram a história da GR. É importante evidenciar novamente a influência da dança na modalidade, a partir da bailarina Isadora Duncan, que, por meio de sua inspiração advinda de modelos da antiga linha grega, interpretava a música, o ritmo e a dança como forma de expressão do belo. Nesta afirmação, Róbeva e Rankélova (1991) apresentam as primeiras preocupações com a imagem do corpo para e sobre as praticantes dessa modalidade.

Ainda em Laban, que reconstruiu o estudo da coreografia na busca de uma linguagem especial do corpo, é possível perceber uma ampliação de harmonia entre estado de espírito, estética e ideais corpóreos (BARBOSA-RINALDI; MARTINELLI; TEIXEIRA, 2009). Já em Noverre, que em sua influência no ballet suprimiu detalhes da vestimenta dos bailarinos, fazendo com que estes se expressassem com mais liberdade, o corpo é exposto aos olhos de outros assumindo relação entre saúde, beleza e referências sociais.

Esses três atores sociais, portanto, contribuíram decisivamente para que se constituísse a visão estética da modalidade, na qual a referência preponderante é a construção corporal refletida na relação sempre conflituosa entre o corpo da ginasta e o corpo idealizado segundo os parâmetros normativos da sociedade (RÓBEVA; RANKÉLOVA, 1991).

Contudo, para Toledo e Antualpa (2016), a GR vem tratando o campo artístico nas diferentes configurações do código de pontuação, que promovem por ora uma aproximação com as correntes influenciadoras da modalidade, como a dança e a música, e, em outros momentos, ruptura com esta lógica histórica como, por exemplo, a permissão do uso de letras nas composições musicais. Entende-se que por um processo de desenvolvimento interno da modalidade passa a justificativa de tais decisões. Entretanto, observa-se que muitas dessas alterações, que são também de habitus, seguem uma lógica de apreensão mercadológica, que favorece a difusão da modalidade, por um lado, mas que, por outro, coloca em xeque as especificidades culturais conquistadas historicamente pela GR.

No propósito, portanto, de atender necessidades reais do universo esportivo, a exemplo da organização de eventos, da obtenção de um maior espaço na mídia, da maximização dos lucros econômicos etc., têm sido apresentados ao universo da GR determinadas demandas sociais. Nesse particular, uma série de mudanças e implementações passam a ser requeridas, mas não autorizadas pelas instâncias organizacionais da GR sob a justificativa de preservar 
a história da modalidade. Uma dessas mudanças possíveis seria, por exemplo, a inclusão do público masculino na prática da modalidade. Sobre o assunto, Boaventura (2011) informa já ser possível identificar a presença masculina no subcampo da GR na figura de treinadores, árbitros e preparadores físicos. Além do mais, esta questão surge como emergente no contexto da GR, pois há equipes que estimulam práticas masculinas.

Nessa linha de entendimento, ressalta-se que as coreografias apresentadas por homens assumem características próprias e até mesmo mudam certas marcas já incorporadas num esporte orientado por um "distintivo de feminilidade". Além disso, conforme aponta Assis (2010), a participação masculina não deixa a desejar em termos de execução técnica e respeito às exigências propostas nos códigos de pontuação, muito embora a FIG continue não a reconhecendo ou a adotando em eventos mundiais oficiais. Por sua vez, a condição de 0 habitus da prática oficial da modalidade ser monopólio de mulheres sugere que os costumes e comportamentos são sempre motivo de conflito, além de impostos por regulamentações.

Não por acaso, o habitus incorporado pelos agentes pertencentes a um determinado campo se configura por meio das estruturas de percepção, pensamento e ação, organizados a partir do modo de viver, pensar e agir, sobretudo, dos grupos dominantes no campo. A entrada ou não entrada, portanto, de homens em uma área reservadamente feminina pode então ser lida a partir desses embates e tensões estruturantes do subcampo da GR.

\section{GINÁSTICA RÍTMICA: AGENTES DOMINANTES E DOMINADOS}

A Teoria dos Campos de Bourdieu considera o ator social em função das relações objetivas que orientam a estruturação da sociedade, em uma relação dialética entre situação e habitus (MARCHI JÚNIOR, 2001). Nesse sentido, é possível dizer que o campo se caracteriza como um domínio de conflitos internos de interesses, dominações e práticas específicas de um determinado espaço social organizado por dominantes e dominados em disputa por poder, reconhecimento e legitimidade (MEZZAROBA; CONCEIÇÃO, 2014).

A posição na qual o indivíduo pertence no campo está relacionada com o capital, representado pelo acúmulo de forças que o agente pode alcançar e pela apropriação dos bens a partir das formas de capital econômico, materializado pela renda, salário e imóveis; capital social, apresentado pelas relações sociais que podem ser convertidas em recursos de dominação; capital cultural, por saberes e conhecimentos reconhecidos por diplomas e títulos; e capital simbólico, compreendido como prestígio que permite identificar os agentes no espaço social (MARCHI JÚNIOR, 2001).

O equivalente dessas disputas no ambiente da GR pode ser verificado ao notarmos a posição que os países europeus ocupam nesse universo, detendo o monopólio dos títulos, das atuações e performances mais aguardadas, dos prêmios, do prestígio. 0 quadro a seguir remete ao que estamos argumentando: 
Quadro 1 - Participação e resultados da GR em Jogos Olímpicos.

\begin{tabular}{|c|c|c|c|}
\hline & Participação do Brasil & Individual & Conjunto \\
\hline \multirow{3}{*}{$\begin{array}{c}1984 \\
\text { Los Angeles }\end{array}$} & \multirow{3}{*}{ Individual - Rosane Favilla - RJ } & $1^{\circ} \mathrm{CAN}$ & $X$ \\
\hline & & $2^{\circ} \mathrm{ROM}$ & $x$ \\
\hline & & $3^{\circ} \mathrm{GER}$ & $x$ \\
\hline \multirow{3}{*}{$\begin{array}{l}1988 \\
\text { Seul }\end{array}$} & \multirow{3}{*}{$x$} & $1^{\circ}$ URS & $x$ \\
\hline & & $2^{\circ} \mathrm{BUL}$ & $x$ \\
\hline & & 3o URS & $x$ \\
\hline \multirow{3}{*}{$\begin{array}{c}1992 \\
\text { Barcelona }\end{array}$} & \multirow{3}{*}{$\begin{array}{c}\text { Individual - Marta Cristina Schonhorst } \\
\text {-SP }\end{array}$} & 1URS & $x$ \\
\hline & & $2^{\circ} \mathrm{ESP}$ & $x$ \\
\hline & & 3 EUN & $x$ \\
\hline \multirow{3}{*}{$\begin{array}{c}1996 \\
\text { Atlanta }\end{array}$} & \multirow{3}{*}{$x$} & $1^{\circ} \mathrm{UKR}$ & 10 Espanha \\
\hline & & $2^{\circ} \mathrm{RUS}$ & 2 Bulgária \\
\hline & & 3 UKR & 3ํㅡússia \\
\hline \multirow{3}{*}{$\begin{array}{l}2000 \\
\text { Sydney }\end{array}$} & \multirow{3}{*}{ Conjunto do Brasil - $8^{\circ}$ colocação } & $1^{\circ} \mathrm{RUS}$ & 1ำ Rússia \\
\hline & & $2^{\circ} \mathrm{BLR}$ & 2ํㅗielorrússia \\
\hline & & $3^{\circ} \mathrm{RUS}$ & 3 Grécia \\
\hline \multirow{3}{*}{$\begin{array}{c}2004 \\
\text { Atenas }\end{array}$} & \multirow{3}{*}{ Conjunto do Brasil - $8^{\circ}$ colocação } & $1^{\circ} \mathrm{RUS}$ & 1ำ Rússia \\
\hline & & $2^{\circ} \mathrm{RUS}$ & 2o Itália \\
\hline & & 3 UKR & 3 Bulgária \\
\hline \multirow{3}{*}{$\begin{array}{l}2008 \\
\text { Pequim }\end{array}$} & \multirow{3}{*}{ Conjunto do Brasil - $12^{\circ}$ colocação } & $1^{\circ} \mathrm{RUS}$ & 1ํRússia \\
\hline & & $2^{\circ} \mathrm{BLR}$ & $2^{\circ}$ China \\
\hline & & $3^{\circ}$ UKR & 3 Bielorrússia \\
\hline \multirow{3}{*}{$\begin{array}{l}2012 \\
\text { Londres }\end{array}$} & \multirow{3}{*}{$x$} & $1^{\circ} \mathrm{RUS}$ & $1^{\circ}$ Rússia \\
\hline & & $2^{\circ} \mathrm{RUS}$ & 2o Bielorrússia \\
\hline & & 3을 & 3o Itália \\
\hline \multirow{3}{*}{$\begin{array}{l}2016 \\
\text { Rio de Janeiro }\end{array}$} & \multirow{2}{*}{ Conjunto do Brasil - 9º colocação } & 1RUS & 1ํRússia \\
\hline & & $2^{\circ} \mathrm{RUS}$ & $2^{\circ}$ Espanha \\
\hline & Individual - Natália Gaudio - ES & $3^{\circ} \mathrm{UKR}$ & 3ํㅡulgária \\
\hline
\end{tabular}

Fonte: Adaptado de BERNARDI; LOURENÇO, 2014.

Em conformidade com os dados expostos, é possível afirmar que países como Rússia, Ucrânia, Bulgária e Bielorrússia têm se destacado efetivamente no cenário mundial na modalidade. A seleção nacional da Rússia, por exemplo, foi campeã nas provas de individual geral e conjunto nas últimas cinco edições dos Jogos Olímpicos de Verão (FEDERAÇÃO INTERNACIONAL DE GINÁSTICA, 2016).

A tradição na GR de países como Rússia, Bulgária e Bielorrússia recebe influência de diversos aspectos que contribuem positivamente para este desenvolvimento técnico refinado na modalidade. De acordo com as características da modalidade, o nível técnico, as cargas e condições de treinamento, a formação profissional, a estética, entre outros fatores, são fundamentais no alcance de um alto nível de desempenho esportivo (LOURENÇO, 2015).

Ainda segundo Lourenço (2015), um dos pontos importantes para o sucesso dos países europeus na GR ocorre em virtude do trabalho de base desenvolvido e direcionado pelas próprias federações. A autora também sugere que mesmo o Brasil sendo um país de território nacional grande, a CBG "[...] poderia se responsabilizar em capacitar seus treinadores 
ou elaborar ao menos recomendações aos treinadores de iniciação na tentativa de minimizar este problema de décadas" (LOURENÇO, 2015, p. 47). Na Rússia a preocupação com a técnica clássica acompanha a formação das ginastas desde a iniciação até a equipe principal (PEREIRA, 2013).

Além dos cuidados com a base, outro fator que pode garantir bons resultado é a permanência de treinadoras experientes e qualificadas para dirigir a equipe nacional. Lourenço (2015) acrescenta que países com tradição na modalidade costumam manter suas treinadoras por muito tempo à frente de suas equipes nacionais, "[...] Irina Vinner é a treinadora chefe da Rússia desde a divisão das Repúblicas da antiga União Soviética, 1977. A famosa treinadora búlgara Neska Róbeva permaneceu à frente das equipes de seu país por aproximadamente 25 anos" (p. 60).

Ademais, esse núcleo de formação possui um suporte estrutural e profissional para as ginastas. As ginastas russas contam com um centro de treinamento e aparelhos de última geração, coreógrafos, profissionais de ballet, preparadores físicos, fisioterapeutas, estilistas, consultores especialistas para cada aparelho, enfim, uma estrutura fundamental no auxílio da preparação da equipe (PEREIRA, 2013).

Outro ponto apresentado como importante no julgamento das composições coreográficas da GR é a questão artística, que perpassa pela relação música e movimento, bem como a apresentação estética da ginasta. A vestimenta utilizada segundo o Código de Pontuação específico da modalidade deve estar relacionada com o contexto no qual a ginasta irá se apresentar durante a execução de sua série.

No capítulo que trata sobre a apresentação da equipe de GR da Rússia nos Jogos Olímpicos de Londres, em 2012, o estudo de Pereira (2013) analisa a posição da equipe minutos antes de entrar no tablado de competição e observa os corpos à espera da chamada do locutor, "[...] ornamentados por um rico collant, a vestimenta de apresentação, cujo poder é apresentado através da vivacidade dos cristais que o decoram" (PEREIRA, 2013, p. 34). Retrata a autora ainda que: "Os bordados majestosos dos collants reforçam o investimento financeiro que é colocado sobre as ginastas" (PEREIRA, 2013, p. 34).

O corpo técnico, apresentado por Pereira (2013), perpassa pela execução perfeita dos movimentos, corpos fortes e ágeis, adquiridos com uma carga de treino extenuante devido às inúmeras repetições. Segundo Laffranchi (2001), técnica da seleção brasileira durante dez anos (LOURENÇO, 2015), a preparação física na GR deve ser voltada para os próprios movimentos da modalidade, assim como o treinamento das qualidades físicas. A autora sugere as aulas de ballet como parte da preparação física, como forma de "[...] aprofundar o aprendizado da técnica do trabalho corporal" (LAFFRANCHI, 2001, p. 32).

Entretanto, Porpino (2004, p. 124) adverte que a estética corporal da modalidade "[...] está atrelada aos movimentos que esse mesmo corpo é capaz de realizar na modalidade e repercute também nas possibilidades de manter a elegância, a graça e a exuberância nas execuções das séries". A autora acrescenta que a busca por uma estética corporal que se aproxime dos padrões internacionais da modalidade começa antes mesmo do treinamento, na escolha das ginastas na composição de uma equipe. "As preocupações com um corpo que atenda aos padrões estéticos necessários para garantir boas performances é o ponto relevante na escolha e manutenção de ginastas em equipes que pretendem participar de competições internacionais" (PORPINO, 2004, p. 124). 
Mas, afinal, que estética corporal é essa? Segundo Porpino, "A estética do corpo que se pretende na GR é uma estética centrada no modelo de um corpo esguio e longilíneo, padrão de corpo das ginastas de alto nível que têm garantido medalhas olímpicas" (2004, p. 124). A autora ainda revela que para as ginastas brasileiras os cuidados com o corpo são imprescindíveis, já que seus corpos são bastante diferentes dos corpos das ginastas europeias. A pesagem diária para o controle de peso é necessária e corrobora o que foi afirmado de que este momento faz parte da construção do habitus da modalidade (PORPINO, 2004).

Para Lourenço (2015), apesar dos países europeus ainda deterem a hegemonia na modalidade, outros países, como o Brasil, vêm ganhando espaço no cenário internacional, ainda com dificuldades no treinamento de alto rendimento com o foco em grandes competições, mas com resultados de certa forma expressivos. A autora acrescenta que o foco da GR brasileira começou a mudar em 1997, quando a CBG oficializou a Seleção Brasileira de Conjunto, pois se começaram a perceber as possíveis chances de medalhas em competições internacionais. As consequências desta mudança vieram imediatamente com a conquista da medalha de ouro nos Jogos Pan-Americanos de Winnipeg em 1999, conquista essa que deu notoriedade ao Brasil no continente americano. O Brasil repetiu o feito da medalha de ouro nas edições seguintes dos Jogos Pan-Americanos, Santo Domingo - 2003, Rio de Janeiro - 2007, Guadalajara - 2011 e Toronto - 2015, além de participar de quatro edições dos Jogos Olímpicos, classificando-se para duas finais em Sydney - 2000 e Atenas - 2004 (LOURENÇO; BARBOSA-RINALDI, 2014; LOURENÇO, 2015).

A conquista de melhores resultados de equipes brasileiras revela um novo e diferente movimento entre os países presentes nessas competições esportivas. Ao mesmo tempo em que o Brasil assume a posição de dominado neste subcampo esportivo, ele referenda suas práticas, exemplos e culturas de treinamento como referência para outras equipes. A lógica se inverte quando então se constrói a análise, por exemplo, a partir de campeonatos pan-americanos, nos quais o Brasil assume papel dominante, informando novos habitus, em um novo campo social com outros e diferentes conflitos internos mediados por interesses (BOURDIEU, 1996).

A logicidade desse processo se expressa, por exemplo, a partir dos resultados obtidos em escala internacional pela GR brasileira. No ano de 2014, o Brasil chegou ao Top 10 da FIG, posição alcançada pelas dez principais seleções no ranking da FIG, no qual permanece até hoje, atrás apenas de países da Europa e da Ásia, sendo o país americano melhor colocado (FEDERAÇÃO INTERNACIONAL DE GINÁSTICA, 2016). Nos Jogos Olímpicos do Rio de Janeiro, tivemos a participação de 24 países, sendo 14 nas provas de conjunto (RIO, 2016). Dentre esses 14 países apenas dois são do continente americano, a saber, Brasil e Estados Unidos, sugerindo que, mesmo com algumas dificuldades, o desenvolvimento ocorrido na GR brasileira vem possibilitando que nossa seleção componha o grupo seleto de países que participaram da mais recente edição do maior megaevento esportivo mundial.

\section{CONSIDERAÇÕES FINAIS}

Pelo teor do que aqui foi exposto, é possível afirmar que a GR atualmente ocupa um lugar singular no campo esportivo, pois suas manifestações atendem a um universo complexo de indivíduos com diferentes interesses e objetivos. Porém, independentemente do trato dado à modalidade, são respeitados costumes, tipos de práticas e estruturas de espaços e tempos 
dos movimentos. Isto é, do alto nível à iniciação ou do esporte competitivo à participação há normas que são respeitadas e seguidas a partir dos princípios da modalidade.

Afirma-se então a existência de uma habitus que norteia comportamentos e ações das (e dos) praticantes da GR, tendo por referência a conformação de um subcampo esportivo formalizado oficialmente, regido e organizado por órgãos competentes, FIG, CBG e suas federações. Somam-se a este cenário as rotinas de treinamentos, os atributos estéticos exigidos na modalidade e a estruturação de uma prática reconhecida pela FIG como sendo de mulheres.

Para os treinamentos, além de uma organização rígida entre periodização e sistemática de treinos técnicos e físicos, há uma preocupação com o trabalho específico de ballet e expressão corporal que se aproximam de uma perspectiva artística das séries. É nesta visão artística que então se singulariza o habitus da GR, em uma lógica que vincula a modalidade à estrutura de um espetáculo artístico garantido pelo uso de collants, aparelhos e músicas que remetem a uma história contada a partir dos movimentos.

Porém, a imposição da GR ao universo feminino vem sendo quebrada nos últimos anos pela presença de treinadores e árbitros nos eventos esportivos e por equipes masculinas, que ainda não foram reconhecidas pela FIG. Aqui se justifica a continuidade de estudos, pois 0 movimento contínuo do desenvolvimento deste esporte estimula mudanças.

Como última reflexão, chamamos atenção para o dinamismo com que se constituem os processos de dominação neste subcampo. Aqui a lógica perpassa a ideia de localidade, pois o que se verificou é que ao olharmos a GR mundial, a Rússia assume seu papel de dominador neste esporte e o Brasil de dominado. Contudo, se tal análise se restringisse, por exemplo, ao universo das Américas, mudaria o cenário entre dominantes e dominados e assim por diante.

Nesse propósito, as evidências apresentadas estimulam novos questionamentos, no sentido de fortalecer princípios e propostas de trabalho com o esporte, principalmente na realidade brasileira. A pretensão não está em qualificar um trabalho técnico, mas sim interpretar situações e ações que hoje perpassam por eventos, ginásios e órgãos dirigentes da GR, e que podem impactar na expansão da modalidade. Fica aqui o registro de um momento iniciado que tem um caminho a ser percorrido.

\section{REFERÊNCIAS}

ASSIS, Marília Del Ponte de. Composição coreográfica em GR: do compreender ao fazer. Motrivivência, v. 22, n. 35, p. 279-285, dez. 2010.

BARBOSA-RINALDI, leda Parra; MARTINELLI, Telma Adriana Pacífico; TEIXEIRA, Roseli Terezinha Selicani. Ginástica Rítmica: aspectos histórico-culturais e técnico-metodológico dos aparelhos. Maringá: Eduem, 2009.

BERNARDI, Luciane Maria de Oliveira; LOURENÇO, Márcia Regina Aversani. Ginástica rítmica: ensinando corda, arco e bola. Várzea Paulista: Fontoura, 2014.

BOAVENTURA, Patrícia Luiza Bremer. Técnica, dor, feminilidade: educação do corpo na ginástica rítmica. 2011. 162 f. Dissertação (Mestrado em Educação) - Universidade Federal de Santa Catarina, Florianópolis, 2011. 
BOURDIEU, Pierre. Questões de Sociologia. Rio de Janeiro: Marco Zero, 1983a.

BOURDIEU, Pierre. Como é possível ser esportivo? In: Questões de sociologia. Rio de Janeiro: Marco Zero, 1983b. p. 136-153.

BOURDIEU, Pierre. Razões práticas. Campinas, SP: Papirus, 1996.

BOURDIEU, Pierre. O poder simbólico. 3. ed. Rio de Janeiro: Bertrand Brasil, 2000.

BOURDIEU, Pierre. Coisas ditas. São Paulo: Brasiliense, 2004.

CAVALCANTI, Loreta Melo Bezerra. Beleza e poder na Ginástica Rítmica: reflexões para a educação física. 2008. 134 f. Dissertação (Mestrado em Educação) - Universidade Federal do Rio Grande do Norte, Natal, 2008.

FEDERAÇÃO INTERNACIONAL DE GINÁSTICA. [Site oficial], 2016. Disponível em: < $\underline{\text { htp:/// }}$ www.fig-gymnastics.com/site/index.php>. Acesso em: 09 ago. 2016.

HERNÁNDEZ, Alejandra O'farril; BOUZA, Amalia Santos. Gimnasia rítmica desportiva. Buenos Aires: Stadium, 1982.

LAFFRANCHI, Bárbara. Treinamento desportivo aplicado à ginástica rítmica. Londrina: UNOPAR, 2001.

LOURENÇO, Márcia Regina Aversani. Ginástica Rítmica no Brasil: a (r) evolução de um esporte. 183 f. Dissertação (Mestrado em Educação Física), Universidade Metodista de Piracicaba: Piracicaba, 2003.

LOURENÇO, Márcia Regina Aversani. O inconstante código de pontuação da Ginástica Rítmica. In: PAOLIELO, Elizabeth; TOLEDO, Eliana de (org.). Possibilidades da Ginástica Rítmica. São Paulo: Phorte, 2010. cap. 4, p. 111-142.

LOURENÇO, Márcia Regina Aversani. A seleção brasileira de conjuntos de Ginástica Rítmica: perfil de ginastas e treinadoras, estrutura técnica e administrativa e o habitus construído. 2015. 188 f. Tese (Doutorado em Educação Física) - Universidade Estadual de Maringá, Maringá, 2015.

LOURENÇO, Márcia Regina Aversani; BARBOSA-RINALDI, leda Parra. O conjunto na Ginástica Rítmica. In: SCHIAVON, Laurita Marconi; BORTOLETO, Marco Antonio Coelho; NUNOMURA, Myrian; TOLEDO, Eliana de (org.). Ginástica de alto rendimento. Várzea Paulista, SP: Fontoura, 2014. p. 43-64

MARCHI JÚNIOR, Wanderley. "Sacando" o voleibol: do amadorismo à espetacularização da modalidade no Brasil (1970-2000). 2001. 267 f. Tese (Doutorado em Educação Física) Faculdade de Educação Física, Universidade Estadual de Campinas, Campinas, 2001.

MEZZAROBA, C.; CONCEIÇÃO, D. M. "Os herdeiros": questões sobre o campo esportivo. Revista Linhas, v. 15, n. 29, p. 317-340, jul./dez. 2014.

PAOLIELLO, Elizabeth; TOLEDO, Eliana de. Possibilidades da Ginástica Rítmica. São Paulo: Phorte, 2010.

PATRÍCIO, Tamiris Lima; BORTOLETO, Marco Antonio Coelho; CARBINATTO, Michele Viviene. Festivais de ginástica no mundo e no Brasil: reflexões gerais. Revista Brasileira de Educação Física e Esporte, v. 30, n. 1, p. 199-216, jan./mar. 2016. 
PEREIRA, Hosana Cláudia Matias da Costa. Ginástica Rítmica: um concerto para o corpo. 2013. 150 f. Dissertação (Mestrado em Educação Física) - Universidade Federal do Rio Grande do Norte, Natal, 2013.

PIRES, Veruska. Ginástica Rítmica: um contributo pedagógico para as aulas de Educação Física. 2003. 133 f. Dissertação (Mestrado em Educação Física) - Universidade Federal de Santa Catarina, Florianópolis, 2003.

PORPINO, Karenine de Oliveira. Treinamento da Ginástica Rítmica: reflexões estéticas. Revista Brasileira de Ciências do Esporte, v. 26, n. 1, p. 121-133, set. 2004.

RIO. Jogos Olímpicos do Rio de Janeiro. [Site oficial] 2016. Disponível em: <https://www. rio2016.com/>. Acesso em: 13 ago. 2016.

RÓBEVA, Neska; RANKÉLOVA, Margarita. Escola de campeãs: ginástica rítmica desportiva. São Paulo: Ícone, 1991.

ROMA, Ana. A satisfação com a imagem corporal e a propensão para as desordens alimentares em praticantes de GR. 2003. 152 f. Dissertação (Mestrado em Licenciatura) Universidade do Porto. Faculdade de Ciência do Desporto e Educação Física, 2003.

SOUZA, Juliano de; MARCHI JÚNIOR, Wanderley. Por uma sociologia reflexiva do esporte: considerações teórico-metodológicas a partir da obra de Pierre Bourdieu. Movimento, v. 16, n. 1, p. 293-315, jan./mar. 2010.

SOUZA, Juliano de; MARCHI JÚNIOR, Wanderley. Bourdieu e a Sociologia do Esporte: contribuições, abrangência e desdobramentos teóricos. Tempo Social, v. 29, p. 243-286, 2017.

TOLEDO, Eliana de. ANTUALPA, Kizzy. A valorização dos aspectos artísticos do Código de Pontuação na Ginástica Rítmica: uma análise das últimas três décadas. Revista Brasileira de Educação Física e Esporte, v. 30, n. 1, p. 119-131, jan./mar. 2016. 